\title{
TOURISM DESTINATION GOVERNANCE V KONTEXTU TEORETICKÝCH POZNATKŠ
}

TOURISM DESTINATION GOVERNANCE IN THE THEORETICAL CONTEXT

\section{ING. ANDREA HOLEĠNSKÁ, PH.D. BC. MARKÉTA NOVOTNÁ}

\author{
Katedra regionální ekonomie a správy $\mid$ Depart. of Regional Economics and Administration \\ Ekonomicko-správní fakulta Faculty of Economics and Administration \\ Masarykova univerzita Masaryk University \\ $\triangle$ Lipová 41 a, 60200 Brno, Czech Republic \\ E-mail: holesinska@econ.muni.cz.
}

\begin{abstract}
Anotace
Problematika tourism destination governance (vládnutí turistické destinaci) je v zahranil i aktuálním

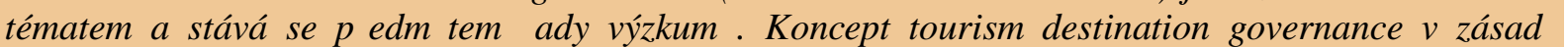
rozg்Śsje teorii destina! ního managementu (Bieger, 1996; Bratl a Schmidt, 1998; Ritchie a Crouch, 2003, Holeğinská, 2012), jehoǵ podstatou je spolupráce a vztahy (vazby) mezi aktéry cestovního ruchu, které jsou zkoumány pomocí teorií interorganiza! ních sití (Alter a Hage, 1993). Teorie sítí vğak nejsou schopny detailn Đzachytit povahu a zdroje vzájemných interakcí, a proto se stŚsedem zájmu stává koncept destination governance vyuğ́vající teorie corporate governance (Beritelli, Bieger a Laesser, 2007; Nordin a Svensson, 2007; Baggio, Scott a Cooper, 2010; Pechlaner, Volgger a Herntrei, 2012). PŚsp円jek pŚedkládá pŚedevğm zahraniḷí teoretické poznatky a pŚstupy $k$ problematice tourism destination governance a shrnuje metody pouǵvané touto teorií. Koncept tourism destination governance je souḷasné dán do kontextu sinstitucionálními sm ny teorie regionálního rozvoje.
\end{abstract}

\section{Klí|lová slova}

tourism destination governance; corporate governance; cestovní ruch; destina! ní management

\section{Annotation}

The issue of tourism destination governance is a current topic abroad and becomes the subject of many studies. Essentially, the concept of tourism destination governance extends the theory of destination management (Bieger, 1996; Bratl and Schmidt, 1998; Ritchie and Crouch, 2003; Holeginská, 2012), which is based on cooperation and relationships between stakeholders, which are examined by the theory of inter-organisational cooperation (Alter and Hage, 1993). The network theory is not able to capture in detail the nature and source of interaction, and therefore the focal point is the concept of destination governance that applied the corporate governance theory (Beritelli, Bieger and Laesser, 2007; Nordin and Svensson, 2007; Baggio, Scott and Cooper, 2010; Pechlaner, Volgger and Herntrei, 2012). The paper reviews foreign theoretical knowledge and approaches to tourism destination governance and summarizes the utilized methods. Moreover, the concept of tourism destination governance is presented in the context of the institutional line of regional development theory.

Key words

tourism destination governance; corporate governance; tourism; destination management

JEL classification: $L 83$, G34 


\section{Úvod}

Destinal ní management je v 90. letech 20. století povaǵován za vysphou formu Śzení destinace (Bieger, 1996), neboŠaplikuje principy (Holeg̈nská, 2012), které posilují spolupráci aktérT cestovního ruchu v destinaci a napomáhají tak rTstu konkurenceschopnosti. Vznikají tak komunitní struktury (Beritelli, Bieger a Laesser, 2007; Bieger, Laesser, Beritelli, 2011) na základク tradice a historie s decentralizovaným vlastnictvím. $Z$ výzkumného hlediska je pŚedm hem zájmu spolupráce a její síth které jsou zkoumány pomocí teorií meziorganizal ní spolupráce (Alter a Hage, 1993; Palmer a Bejou, 1995). Nej! ast $\prod_{\mathrm{i}}$ jsou v tomto kontextu citovány teorie závislosti na zdrojích ${ }^{1}$, teorie vztahové (sociální) zm円hy², teorie racionální volby a teorie transak! ních nákladT.

Díky sílícímu tlaku na konkurenceschopnost dochází v destinacích k proces Tm konsolidace, coǵ si vyğaduje i zmßny v organizal ní struktuŚ destinace ï klí| ová je role strategie. V turisticky vysphých destinacích (ǵvýcarské Alpy) se proto orientují na podnikový typ struktury, který se vyznaḷje vysokou integrací a centrálním Ǎśzenímñ destinace jednou spolel ností, viz DMO 3. generace (Bieger, Laesser, Beritelli, 2011). Takto podnikovク Śzené struktury si vyǵadují komplexnクğ pŚstupy zkoumaní vnitŚích vazeb spolupráce/síth a proto se do popŚdí dostávají teorie coprorate governance, které pov Đğinou vycházejí z teorie vlastnických práv, teorie zastoupení $i^{3}$, teorie transakl ních nákladTa teorie sítí (Beritelli, Bieger a Laesser, 2007).

\section{Metodika}

L̦ lánek má charakter pŚchledové stath pro jejíǵ zpracování byl pouğit normativní pŚstup. Samotný výzkum, resp. detailní reġerǵe odborné literatury k dané problematice, vychází ze základních metod analýzy, syntéza, dedukce-indukce, kompilace a dalğch.

\section{Výsledky výzkumu}

Výzkum v oblasti destinal ního managementu (Bieger, 1996; Bratl a Schmidt, 1998; Ritchie a Crouch, 2003, Holeg̉nská, 2012; Derco, 2012) se orientuje na spolupráci mezi aktéry cestovního ruchu a potaǵmo vytváŚ́ní sítí v destinaci. Díky dynamickému a procesnク orientovanému pŚstupu k destinal nímu managementu, který se vyznaḷ uje strategickým Śzením a silnými vazbami mezi kooperujícími subjekty, se zalínají aplikovat ve výzkumech tḩhto jevT principy corporate governance ${ }^{4}$. V kontextu destinací se pak objevuje pojem (tourism) destination governance (Beritelli, Bieger a Laesser, 2007; Bieger, Laesser, Beritelli, 2011), který klade v Iğ dTraz na práva a zájmy aktérT cestovního ruchu a zkoumá zdroje vzájemných interakcí. Zahrnut je proces rozvoje neformálních vztahT, znalostí a dTvクyy utváŚsící dynamický rozmグ nepostradatelný pro analýzu utváśení daných sítí.

\section{Corporate governance}

Beritelli, Bieger a Laesser (2007) vyuğ́vají teorii corporate governance, s jejíǵ pomocí se snağ́ vysv クlit vznik a vývoj Śdících struktur v destinaci. Aplikace konceptu na turistické destinace spol ívá ve stanovení a vypracování pravidel a postupT pro politiku, stejnクjako pro obchodní strategie. Dále autoŚ pŚedstavují vliv na chování jednotlivcT a distribuci s vyugóitím teorie vlastnických práv a teorie zastupitelství, která pŚedpokládá v dTsledku asymetrických informací oportunistické chování manaǵerT. Thnto dvク̣na teoriím pŚkládají autoŚ význam pŚdevơm z hlediska pochopení vztahT

\footnotetext{
${ }^{1}$ Ressource dependency theory

${ }^{2}$ Relations (social) exchange theory

${ }^{3}$ Agency theory

${ }^{4}$ Corporate governance se zabývá strukturami a systémy Śzení, v rámci kterých jsou manaǵeś odpovßlni, thn kteŚ mají oprávn hný podíl/zájem v organizaci. O corporate governance se hovoŚ z dTvodT oddクení vlastníkT a manaǵerského Śzení organizace; z dTvodT ! etných skandálTm v 90. letech minulého století; a dTvodu zvýğení odpovhlnosti za zájmy g̈roké masy aktérT. (Johnson, Scholes, Whittington, 2008)
} 
mezi zúl astnḩými stranami, tedy mezi místním obyvatelstvem a jednotlivci nebo firmami, neboŠ vysvhlují potŚbu spole! nosti kontrolovat a sledovat linnosti jednotlivých firem a podnikatelT, kteŚ usilují o své ekonomické zájmy hojným vyuǵ̛váním pŚrodních a kulturních zdrojT destinace, které jsou vnímány jako veŚjný majetek. Kromநthhto dvou výǵe zmín円yých teorií se Beritelli, Bieger a

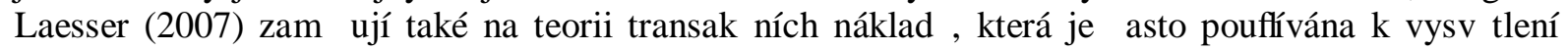
rTzných institucionálních uspoŚídání, ve kterých se transakce odehrávají, a teorii sítí. AutoŚ dochází k záv円u, ǵe corporate governance výraznク pomáhá pŚ vytváŚení vzorcT pro koncept destination governance, viz Obr. 1.

\section{Obr. 1: PŚ hled teorií corporate governance a jejich perspektivy}
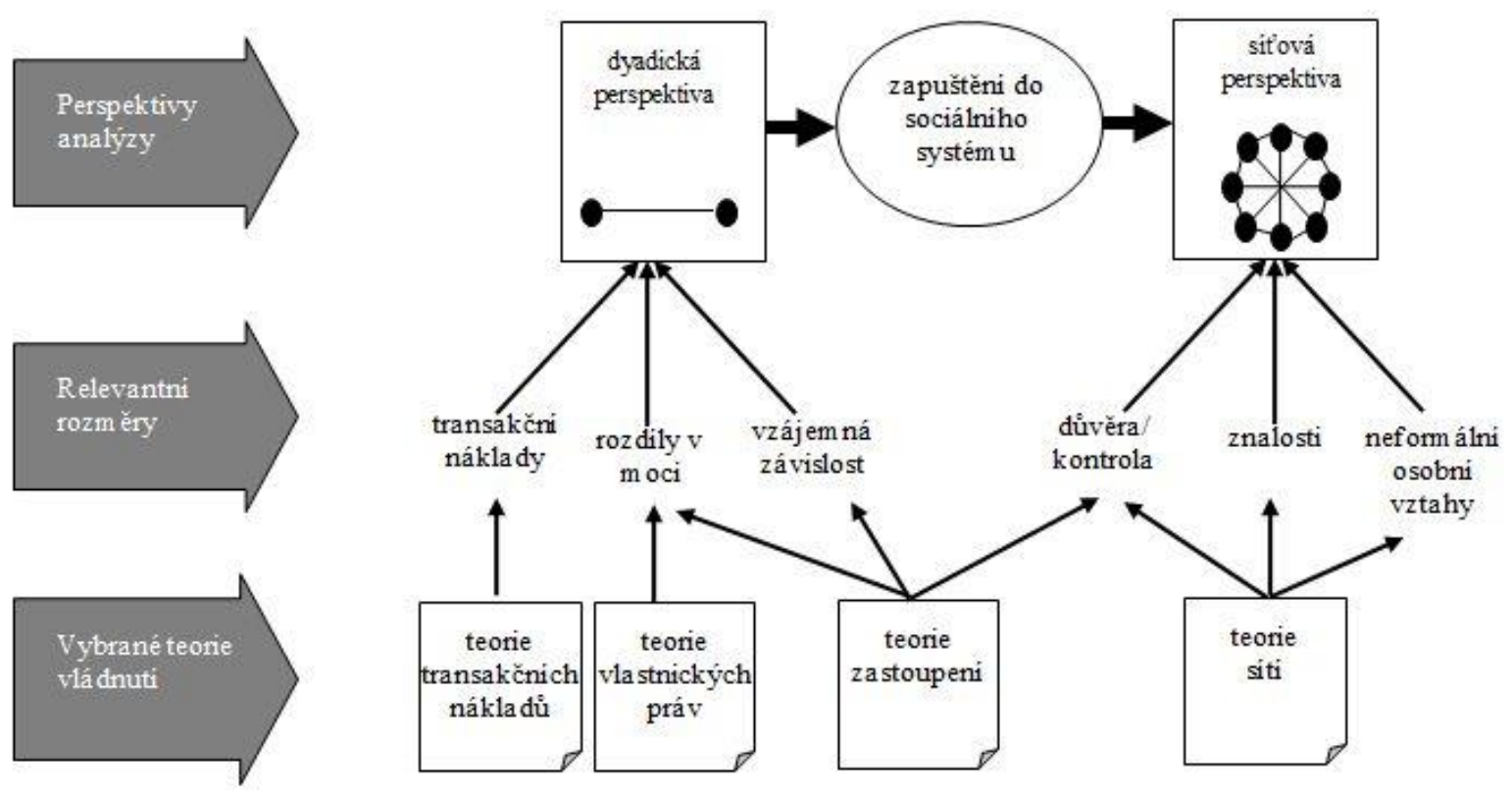

Zdroj: Beritelli, Bieger a Laesser (2007:97)

Vyuǵití prvkT corporate governance v oblasti cestovního ruchu zkoumá i Pechlaner, Raich a Kofink (2011). Za úl elem dalğho rozvoje a profesionalizace organizací cestovního ruchu povaǵují za nezbytné pŚjetí prvkT tohoto konceptu, protoǵe organizacím nabízí Śsdu nástroj丁, které lze vyuğ́i za úl elem Śzení, kontrolování a monitorování, a umoğḱuje implementaci definovaných struktur a norem. Úsphh implementace závisí podle autorT pŚdevğm na specifických vlastnostech organizace, které spoḷ ívají v pŚstupu, struktuŚ organizace, dovednostech managementu a zamß̧tnancT, stejnクjako v jejich schopnostech spolupráce a souhry.

\section{Teorie sítí}

Dle Pechlanera, Volggera a Herntreie (2012) se koncept destination governance zakládá na sítích a pŚ́dstavuje formu sebeorganizování destinace cestovního ruchu, zaloǵené na spolupráci rTzných zapojených aktérT a formované institucionálními souvislostmi a pravidly organizace. Je zamłśen na vztahy, sítク a partnerství mezi soukromým a veŚjným sektorem. V jejich podání se destinal ní management nachází na rozhraní mezi destination governance a corporate governance, viz Obr. 2. 
Obr. 2: Model destinace v pojetí destination governance

DESTINACE

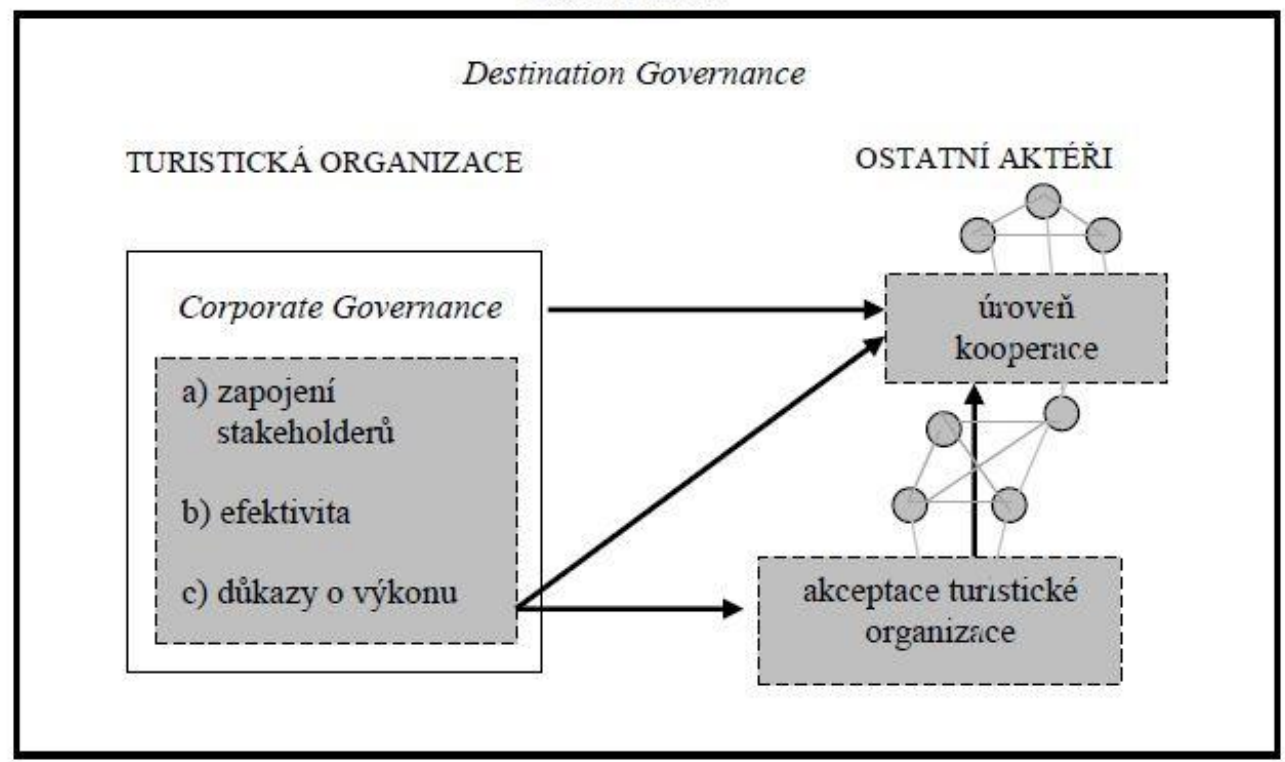

Zdroj: Pechlaner, Volgger, Herntrei (2012:165)

Nordin a Svensson (2007) poukazují na spojitost mezi strukturou vládnutí (governance) a rozvojem destinace, respektive procesy a výkonem. Jejich výsledky jen potvrzují pŚdchozí zjiğhí, viz Beritelli, Bieger a Laesser (2007), ǵ́ vztahy mezi soukromým a veŚejným sektorem jsou zaloǵeny na dTvrh́se, neformální struktuŚ a strategickém konsenzu a mají pozitivní dopad na úroveR rTstu destinace.

Baggio, Scott a Cooper (2010) vymezují a analyzují vztahy v rámci destinace a pro charakterizaci interakce zúlastnĐyých stran vyuğ́vají vlastnosti sítí, které jsou dTleǵité pro pochopení principJ destination governance a pŚdstavují moǵnosti jejich zkvalitn円í́.

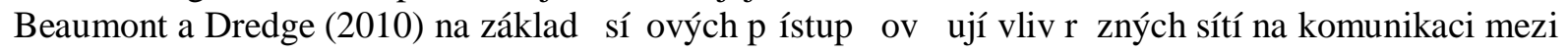
aktéry, dTv ク̧u, legitimitu a transfer znalostí. StŚedem pozornosti jsou lokální struktury.

\section{Sociální teorie}

Bramwell (2011), zabývající se vlivem státu na cestovní ruch, uvádí, ǵe výzkumy v oblasti destination governance by $\mathrm{m} \eta_{\mathrm{y}}$ více vyuğivat sociálních teorií. Tento pŚstup mTǵe podle Bramwella (2011) nabídnout lepğ pohled na okolnosti státních intervencí, které ovlivRují cestovní ruch a udrớitelnost v destinacích. Bramwell a Lane (2011) poukazují na to, ǵe koncept sociálních teorií mTğe poskytnout uğitel ný náhled do problematiky cestovního ruchu a jeho udrğitelnosti. Vymezují dva pŚstupy, které lze pŚ vedení výzkumT v dané oblasti vyuğít. První pŚstup zvaǵuje procesy a druhý bere v úvahu konkrétní role a ḷinnosti veŚjného sektoru.

\section{Institucionální smDy teorie regionálního rozvoje}

U konceptu tourism destination governance je moǵné sledovat paralely s institucionální ekonomií, která je hojnநvyuğivána pŚ objasŔování rozdílT v hospodáŚském rTstu, pŚ analýze motivT chování ekonomických aktérT nebo rolí politické moci a zájmových skupin ve fungování ekonomiky (Blaǵek a Uhlíś 2011:60). Dle Voigta (2008:29) odpovídá institucionální ekonomie na otázky, jak pJsobí instituce na rTst a rozvoj. Na mikroekonomické úrovni zkoumá podle Voigta (2008:29) vliv institucí na to, jak soukromí aktéŚ uspoŚ́dávají opakované transakce, jak ovlivŔují sm円hu statkT mezi soukromými aktéry a jak ovlivŔují motivace ke kolektivnímu jednání. 
V kontextu institucionálních smク̣T teorie regionálního rozvoje se setkáváme s vysvhlením pŚ| in regionálních rozdílT za pouğíi metodického aparátu institucionální ekonomie, ekonomické sociologie a kulturní teorie. $\mathrm{V}$ thehto sm/̧ech je kladen dTraz na význam inovací a znalostí pro vznik a udrǵení konkuren! ní výhody. Stejnゆtak se zde setkáváme se snahou zformulovat normativní doporul ení pro zlepǵení konkurenceschopnosti regionT(Blaǵek a Uhlíś 2011:175).

Z perspektivy institucionální ekonomie nahlíǵ na oblast destination governance napŚ Zhang (2011). UpozorŔuje, ǵe studií, které by aplikovaly institucionální pŚstup na analýzu tourism destination governance, je velmi málo, proto nebyl také dosud rozvinut gádný teoretický rámec. Zhang (2011) v kontextu institucionální ekonomie zkoumá tourism destination governance ze dvou hledisek. V tom prvním definuje rTzné formy a následnクpozoruje jejich dopad a výkon v daném institucionálním prostŚ́dí. Ve druhém sleduje vznik a vývoj modelu z pohledu historického. Spíġe neǵ konkrétní výsledky pŚnáğ výzkumné otázky, které by mohly být zodpovßzeny dalğmi výzkumníky. Pro tyto pŚpady doporul uje vyugóití kvalitativních pŚpadovĐorientovaných studií. Dalğ postupy by $\mathrm{m}$ y ur ụ it

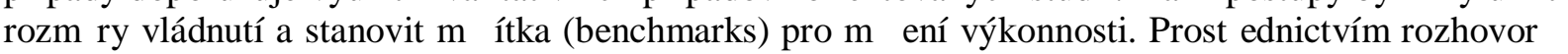
a dotazník丁 navrhuje identifikovat rTzné formy struktury vládnutí destinaci, s následným hodnocením jejich výkonu, a analyzovat dopady.

Jednotlivé interakce v rámci cestovního ruchu zkoumá v kontextu institucionální ekonomie i Halkier (2013) a Beaumont a Dredge (2010), kteŚ zjistili, ğe efektivita vládnutí v destinaci pŚ dosahování cílT zainteresovaných stran závisí na úl innosti institucionálních struktur a procesT, dostupnosti zdroj丁 a kvalifika! ních pŚedpokladech. AutoŚ povaǵují institucionální struktury za rámec utváŚjící organizaci a tvarující autonomii, vnitŚí soudrónost a organiza! ní disciplínu.

\section{Metody pouǵvvané $\mathrm{v}$ rámci tourism destination governance}

$\mathrm{Z}$ výğe citovaných výzkumných studií je zŚsjmé, ǵe $\mathrm{k}$ objasnク̧í poznatk丁 o tourism destination governance se vyuğ́vá kvalitativních výzkumných metod v podobクpŚpadových studií, kdy jsou nej! astクi aplikovány (Śzené/polostrukturované) rozhovory s respondenty.

Tab. 1: PŚ sled metod

\begin{tabular}{|l|l|l|}
\hline AutoŚ & Metoda & \\
\hline Beritelli, Leasser, Bieger (2007) & PŚpadová studie & $\begin{array}{l}\text { Analýza interních materiálT } \\
\text { ř ízené rozhovory }\end{array}$ \\
\hline Pechlaner, Raich, Kofink (2011) & PŚpadová studie & Dotazníkové ǵtŚnín \\
\hline Pechlaner, Volgger, Herntrei (2012) & PŚpadová studie & Polostruktruované rozhovory \\
\hline Nordin, Svensson (2007) & PŚpadová studie & Polostrukturované rozhovory \\
\hline Baggio, Scott, Cooper (2010) & Simula! ní model & SíSová analýza \\
\hline Beaumont, Dredge (2010) & Explorativní pŚpadová studie & $\begin{array}{l}\text { Analýza interních materiálT } \\
\text { Polostrukturované rozhovory }\end{array}$ \\
\hline
\end{tabular}

\section{Závf}

Z reġerǵe literatury vyplývá, ǵe úsphch implementace konceptu tourism detination governance závisí na organizaci, její struktuŚ, dovednostech a schopnostech managementu a zamß̧̧nancT, stejnךjako na spolupráci a souhŚ mezi aktéry. Jelikoǵ se koncept zakládá na sítích, které ovlivRují komunikaci, legitimitu a transfer znalostí, je nutné pŚ procesu implementace rozvíjet také neformální vztahy a

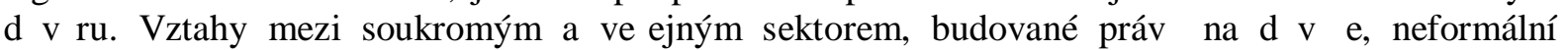
struktuŚ a strategickém konsenzu, mají pozitivní dopad na úroveŔ rozvoje destinace. Posilování prvkT spolupráce a integrace mezi vládními organizacemi zapojenými do cestovního ruchu a mezi vládou a soukromým sektorem by $m \eta_{0}$ pŚedstavovat pro tvTrce politiky a manaǵery hlavní zájem. Efektivita tourism destination governance a dosahování cílT závisí také na úl innosti institucionálních struktur a procesT, dostupnosti zdroj丁 a kvalifikal ních pŚdpokladech. 
Pro hlubğ rozbor uvedených poznatkT se nabízí tyto moǵné výzkumné otázky:

- Jak struktura vládnutí a formy institucionálního uspoŚídání vzájemných interakcí ovlivŔují výkon destinace, resp. její rozvoj?

- Do jaké míry ovlivŔují odlig̉é zájmy aktérT, kteŚ sledují url ité výhody, vládnutí v destinaci?

- V jakém rozsahu mTǵge mít akceptace organizace cestovního ruchu ostatními aktéry cestovního ruchu vliv na vládnutí v destinaci?

\section{Literatura}

[1] ALTER, C., HAGE, J., (1993). Organizations Working Together. Newbury Park/London/New Delhi: Sage Publications. ISBN 0803948271.

[2] BAGGIO, R., SCOTT, N., COOPER, CH., (2010). Improving tourism destination governance: a complexity science approach. Tourism Review, vol. 65, iss. 4, pp. 51ї60. DOI 10.1108/16605371011093863.

[3] BEAUMONT, N., DREDGE, D., (2010). Local tourism governance: a comparison of three network approaches. Journal of Sustainable Tourism, vol. 18, iss. 1, pp. 7-28. DOI 10.1080/09669580903215139.

[4] BERITELLI, P., BIEGER, T., LAESSER, CH., (2007). Destination Governance: Using Corporate Governance Theories as a Foundation for Effective Destination Management. Journal of Travel Research, vol. 46, pp. 96ï 107. DOI 10.1177/0047287507302385.

[5] BIEGER, T., (1996). Management von Destinationen und Tourismusorganisationen. München: Oldenburg Verlag.

[6] BIEGER, T., LAESSER, CH, BERITELLI, P., (2011). Destinationsstrukturen der 3. Generation Ï Der Anschluss zum Markt. St. Gallen: Universität St. Gallen. p. 34.

[7] BLAG̣EK, J., UHLÍřr, D., (2011). Teorie regionálního rozvoje. Nástin, kritika, implikace. Praha: Karolinum, Univerzita Karlova v Praze. ISBN 978-80-246-1974-3.

[8] BRAMWELL, B., (2011). Governance, the state and sustainable tourism: a political economy approach. Journal of Sustainable Tourism, vol. 19, iss. 4ї 5, pp. 459ї 477. DOI 10.1080/09669582.2011.576765.

[9] BRAMWELL, B., LANE, B., (2011). Critical research on the governance of tourism and sustainability. Journal of Sustainable Tourism, vol. 19, iss. 4ї 5, pp. 411ї 421. DOI 10.1080/09669582.2011.580586.

[10] BRATL, H., SCHMIDT, F., (1998). Destination Management. Wien: Wirtschaftsministerium, ÖARRegionalberatung, $\mathrm{GmbH}$.

[11] DERCO, J., (2013). Destination Governance in the Czech Republic, Slovakia and Poland. Tourism Planning and Development, vol. 10, iss. 3, pp. 354 ï 364.

[12] HALKIER, H., (2013). Innovation and Destination Governance in Denmark: Tourism, Policy Networks and Spatial Development. European Planning Studies, pp. 1-12. DOI 10.1080/09654313.2013.784609.

[13] HOLEĠNSKÁ, A., (2012). Destina! ní management jako nástroj regionální politiky cestovního ruchu. Brno: Masarykova univerzita. ISBN 9788021058477.

[14] JOHNSON, G., SCHOLES, K., WHITTINGTON, R., (2008). Exploring corporate strategy. Text \& cases. Harlow: Pearson Education Limited.

[15] LAWS, E., RICHINS, H., AGRUSA, J., (2011). Tourist destination governance: Practice, theory and issues. CABI Publishing.

[16] NORDIN, S., SVENSSON, B., (2007). Innovative destination governance: The Swedish ski resort of Åre. Entrepreneurship and Innovation, vol. 8, iss. 1, pp. 53 ï 66.

[17] PALMER, A., BEJOU, D., (1995). Tourism destination marketing alliances. Annals of Tourism Research, vol. 22, iss. 3, pp. 616-629. DOI 10.1016/0160-7383(95)00010-4.

[18] PECHLANER, H., RAICH, F., KOFINK, L., (2011). Elements of corporate governance in tourism organization. Tourismos: An International Multidisciplinary Journal of Tourism, vol. 6, iss. 3, pp. 57-76.

[19] PECHLANER, H., VOLGGER, M., HERNTREI, M., (2012). Destination management organizations as interface between destination governance and corporate governance. Anatolia ï An International Journal of Tourism and Hospitality Research, vol. 23, iss. 2, pp. 151 ï 168.

[20] RITCHIE, J. B, CROUCH, G. I., (2003). The competitive destination: a sustainable tourism perspective. Wallingford: CABI publishing. ISBN 0851996647.

[21] VOIGT, S., (2008). Institucionální ekonomie. Praha: Alfa nakladatelství. ISBN 978-80-87197-13-4.

[22] ZHANG, H., (2011). Studies on Tourism Destination Governance from the Perspective of Institutional Economics: Retrospect and Prospect. In 3rd International Conference on Information and Financial Engineering. Vol. 12. Singapore: IACSIT Press.

PŚspnek byl zpracován v rámci grantu MUNI/A/0853/2013 ĂTourism destination governance v kontextu institucionálních sm $\mathbf{3 T}$ teorie regionálního rozvojeñ 